\title{
Assessment of Quality of Shea Butter Sourced from Organic and Inorganic Fields
}

\author{
Baba Musah Bawah $^{1, \mathrm{a}}$, Alimsiwon Karl Afoko ${ }^{1, \mathrm{~b}}$, Albert Kojo Quainoo ${ }^{1, \mathrm{c}}$, Francis Azumah Chimsah ${ }^{2, d}$ \\ Abudu Ballu Duwiejuah ${ }^{3, e^{*}}$, Abdul Halim Abubakari ${ }^{2, f}$ \\ ${ }^{1}$ Department of Biotechnology, University for Development Studies, Tamale, Ghana. \\ ${ }^{2}$ Department of Horticulture, Faculty of Agriculture, University for Development Studies, Tamale, Ghana \\ ${ }^{3}$ Department of Ecotourism and Environmental Management, Faculty of Natural Resources and Environment, University for Development \\ Studies, Tamale, Ghana \\ *Corresponding author

\begin{tabular}{l|l}
\hline A R T I C L E I N F O & A B S T R A C T \\
\hline Research Article & $\begin{array}{l}\text { The objective of the study was to compare selected physical and chemical composition of shea butter } \\
\text { processed from nut sourced from inorganic and organic fields. The treatments were O (shea butter } \\
\text { processed from nut picked from organic fields) and N (shea butter processed from nuts picked from } \\
\text { inorganic fields). These treatments were arranged in a Complete Randomized Design and were } \\
\text { replicated four times in the laboratory for studies of free fatty acids (FFA), pH, peroxide value, } \\
\text { insoluble impurities, unsaponifiable matter, and moisture content. The study revealed that organic } \\
\text { shea butter had lower free fatty acids (FFA), lower moisture content, lower pH, less unsaponifiable } \\
\text { matter, less insoluble impurities and lower peroxide value as compared to inorganic shea butter shea } \\
\text { butter. The lower FFA value of organic shea butter indicates that it can be used for the cosmetic and } \\
\text { pharmaceutical industry and for direct consumption. Hence higher chances that organic shea butter } \\
\text { and attract premium prices in both local and international markets. The study also revealed that there } \\
\text { was a positive relationship between; unsaponifiable matter and moisture content. Insoluble } \\
\text { Keywords: } \\
\begin{array}{l}\text { Free fatty acids } \\
\text { Moisture content } \\
\text { Insoluble impurities } \\
\text { Organic shea butter } \\
\text { Peroxide value }\end{array}\end{array} \begin{array}{l}\text { impurities had a very strong correlation with unsaponifiable matter and moisture content. A very } \\
\text { strong positive correlation was observed between peroxide value and unsaponifiable matter, } \\
\text { moisture content, and insoluble impurities. For good quality butter, nuts should be sourced from } \\
\text { organic fields. }\end{array}$
\end{tabular}

a@bawamusah56@gmail.com

c@aquainoo@uds.edu.gh

e@abalu096@gmail.com b@afokokarl96@gmail.com

f@ahalim@uds.edu.gh
(D) https://orcid.org/0000-0001-7912-9509

iD https://orcid.org/0000-0002-6509-2116

(iD) https://orcid.org/0000-0001-7359-0118

\section{Introduction}

The shea tree (Vitallaria paradoxa) belongs to the sapotaceae family (Caroline et al., 2009). It is a wild plant and dominates the dry savannah belt of Senegal in the Western part of Africa through Sudan to the foothills of the Ethiopian highlands (Boffa, 1999).

Shea a non- timber forest product strives predominantly in the Northern, Upper West, Upper East region of Ghana and parts of the Brong Ahafo region serves as a source of raw material for the shea industry (FAO, 1988). The tree is perennial and deciduous and grows mainly on open slopes (Yidana, 2004).

The shea industry has been predicted to equalize the cocoa industry with time as shea butter becomes the best alternative for cocoa butter (De Muelenaere, 1997; Moore, 2008). It is a triglyceride; mainly from stearic acid and oleic acid. The shea tree is versatile and highly valued not only for the economic and dietary significance of it used as cooking oil but also for the fruit pulp, buck, root and leaves which are used in traditional medicines, wood and charcoal used for cooking fuel (USAID, 2005).

According to Russo and Etherington (2001) shea products are good for use as raw materials for cooking oil, margarine, cosmetics, production of soap, detergents and candles. The aim of the study was to determine the physical and the chemical quality of shea butter sourced from inorganic and organic fields. This may offer scientific evidence for the use of best field management practices that would produce quality shea butter for the cosmetic, pharmaceutical, food industry, detergent industrial and even automobile industries. 


\section{Materials and Methods}

The study was carried out from May 2016 to June 2017 where samples of shea fruits were collected at Kanfiehiyili in the Kumbungu District in the Northern Region of Ghana. The agro-ecological zone of the area is Northern Guinea Savanna. Shea fruits were collected randomly from organic and inorganic fields at Kanfiehiyili in the Northern region of Ghana for a period of two weeks. Organic fields are farm lands that are uncultivated and left to fallow while inorganic fields are farm lands that are cultivated and fertilizers are usually applied.

Shea nut fruits were collected from each of the identified fields and sent to the Spanish Laboratory at the University for Development Studies for processing and storage. The pulps were removed to obtain the shea nuts. The de-pulp shea nut were partially boiled to reduce fungal growth, stop germination process and enhance the removal of the shell from the kernel. The kernel were dried and roasted for butter extraction using the traditional method. The nuts were processed into shea butter. Shea butter were kept into labeled containers and stored in a deep freezer for a period of five days. The shea butter was then transported under standard temperature for analysis of the chemical properties. A total of 48 samples of shea butter; 12 from each of the fields (organic and inorganic fields, respectively) were taken to the Pharmacognosy laboratory of the Kwame Nkrumah University of Science and Technology for analysis.

\section{Method of Extraction of Shea Butter}

The kernel was pounded into smaller pieces using a mortar and a pestle, after which the remnants were scooped using a mixing bowl into a large pot for roasting. There was occasional stirring of the kernel to ensure even roasting. After roasting the mixture was allowed to cool and then grounded into paste. Warm water was added to the paste and kneading continuously with the hand. Kneading continued until the original dirty brown colour of the paste turns grey. Cool water was added and the fat was seen floating on top of the water. A calabash was used to fetch the fat and washed several times to eliminate impurities. The grey fluffy matter was then kept into a large cooking pot and heated at $55^{\circ} \mathrm{C}$. The grey fluffy matter, which is dirty melted and suspended at the top of cooking pot, leaving a brownish solid residue at the bottom of the pot. The oil was then separated into clean containers and cooled whilst stirring until it solidified into solid shea butter.

\section{Determination of Free Fatty Acids}

The FFA value is the number that expresses, in milligrams the quantity of potassium hydroxide required to neutralize the free acids present in $1 \mathrm{~g}$ of the substance. The acid value is often a good measure of the breakdown of the triacylglycerols into free fatty acids, which has an adverse effect on the quality of many lipids.

About $10 \mathrm{~g}$ of the shea butter samples was weighed into a dry $250 \mathrm{ml}$ conical flask. A $50 \mathrm{ml}$ mixture of ethanol and diethyl ether (1:1) was added to dissolve the oil. This was warmed gently with shaking on the water bath $\left(65^{\circ} \mathrm{C}\right)$ for 10 minutes. The solution was cooled, 2 drops of phenolphthalein indicator was added and the mixture titrated against $0.1 \mathrm{M} \mathrm{KOH}$ (factor 0.9980) until a pink colour appears and persist for at least 15 seconds. This was repeated for each sample and the observations recorded. The quantity of free fatty acids $(\mathrm{mg} / \mathrm{g}$ and $\% \mathrm{w} / \mathrm{w})$ were determined using Evans (2002) formula.

\section{Determination of Unsaponifiable Matter}

About $5 \mathrm{~g}$ of each shea butter sample was accurately weighed into a $250 \mathrm{ml}$ round-bottom flask and $50 \mathrm{ml}$ of 0.1 $\mathrm{M}$ potassium hydroxide $(\mathrm{KOH})$ in ethanol was added. Few anti-bumping granules were added and the set-up attached to a reflux condenser. The content was boiled gently for about 1 hour after which the heating was stopped and 50 $\mathrm{ml}$ of distilled water added through the top of the condenser and swirled gently.

The mixture was allowed to cool and transferred into a $250 \mathrm{ml}$ separating funnel. The round-bottom flask and the anti-bumping granules were rinsed repeatedly with $n$ hexane into the separating funnel and enough $n$-hexane (total $50 \mathrm{ml}$ ) added to the content of the separating funnel. This was stoppered and shaken vigorously for 1 minute releasing pressure periodically by inverting the funnel and gently opening the stop-cork.

The two-phase mixture was allowed to stand for about 30 minutes for complete phase separation. The lower soapy-aqueous layer was drained into another separating funnel and washed repeatedly with $50 \mathrm{ml}$ quantities of $n$ hexane.

The $n$-hexane extracts were bulked into another separating funnel and washed severally with $25 \mathrm{ml}$ portions of $70 \%$ ethanol solution. This was continued until further washing yielded no pink coloration upon addition of drops of phenolphthalein to the ethanolic extract.

The purified $n$-hexane extract was then transferred quantitatively into a dry $250 \mathrm{ml}$ flask (weighed) and evaporated over the water bath until a dry residue resulted. This was allowed to further dry in a desiccator for 12 hours and weighed to the nearest $0.1 \mathrm{mg}$. The content of unsaponifiable matter is expressed as a percentage of the test sample using Ethiopian Standard ISO 18609 (2012) formula.

\section{Determination of Moisture Content}

About $20 \mathrm{~g}$ of the fat samples were weighed into tarred porcelain crucibles. This was kept in an oven (thermoScientific, Germany) at $105^{\circ} \mathrm{C}$ for $1 \mathrm{hr}$. The samples were weighed and kept back in the oven at $1 \mathrm{hr}$ intervals until a constant weight was achieved. The amount of moisture lost was calculated by deducting the final weight from the initial weight of the samples (Evans, 2002).

\section{Determination of $\mathrm{pH}$}

Exactly $5 \mathrm{~g}$ of each sample was accurately weighed into $25 \mathrm{ml}$ clean conical flask. This was allowed to melt completely over a water bath $\left(65^{\circ} \mathrm{C}\right)$ and allowed to cool. While the sample was still liquid, the $\mathrm{pH}$ was measured using a $\mathrm{pH}$ meter. Two readings were taken for each sample and an average value determined (Evans, 2002).

\section{Determination of Insoluble Impurities}

About $20 \mathrm{~g}$ of the fat samples were each weighed into $100 \mathrm{ml}$ conical flask and about $50 \mathrm{ml}$ petroleum ether was added and shaken to dissolve completely. This solution was filter into another conical flask using Whatman No 1 
filter paper of known weight. The filter papers were ovendried at $65^{\circ} \mathrm{C}$ for $3 \mathrm{hrs}$ and further dried in a desiccator. These were then weighed and the corresponding weight of impurities retained determined as appropriate. The insoluble impurities were expressed as \% impurities and $\mathrm{mg} / \mathrm{g}$ impurities (Evans, 2002).

\section{Determination of Peroxide Value}

About $20 \mathrm{~g}$ of the fat sample were each weighed into a $250 \mathrm{ml}$ conical flask and dissolved in $30 \mathrm{ml}$ mixture of ethanol and diethyl ether $(1: 1)$.

$10 \mathrm{ml}$ of $15 \%$ potassium iodide solution was added to glacial acetic acid solution. $30 \mathrm{ml}$ of this reagent was pipetted into the dissolved fats and shaken vigorously for about 30 minutes. A yellow colour formed indicating the liberation of iodine.

Five drops of $1 \%$ starch solution was added to the liberated iodine solution. This was titrated against $0.1 \mathrm{~N}$ sodium thiosulphate solution until the blue-black colour disappears at the end point A. A blank titration was performed except the addition of the sample to end point $B$.

The titration was repeated for each sample and the peroxide value determined (ISO 3960, 2007).

\section{Data Analysis}

The data was analysed using GENSTAT software by running ANOVA. The mean values for the various parameters were compared and significant difference observed among the treatments. The level of significance was set at $5 \%$.

\section{Results and Discussion}

The influence of the shea butter source on the free fatty acids, peroxide value and insoluble impurities of the shea butter produced was highly significant $(\mathrm{P}<0.001)$ (Table 1). The unsaponifiable matter and moisture content of the shea butter were also affected $(\mathrm{P}<0.05)$ by the source of shea butter. However, the shea butter source did not influence $(\mathrm{P}>0.05)$ the $\mathrm{pH}$ of the shea butter. Organic shea butter had higher free fatty acids than inorganic shea butter (Table 1). On the other hand, inorganic shea butter had higher moisture content, peroxide value, insoluble impurities and unsaponifiable matter than organic shea butter.

\section{Free Fatty Acids}

The free fatty acid content was low in organic shea butter as compared to the inorganic shea butter. Comparing this result to the Global Shea Alliance Grading of parameters it shows that the lower the FFA value the higher the quality of Shea butter. The free fatty acid content is naturally low in fresh nuts, but increases rapidly through hydrolysis under poor storage conditions. Hydrolysis occurs through the lipolytic activity of the lipase and microorganisms; it is halted by heating and by reducing the moisture content to lower than 8\% (Abedin et al., 2015). Based on Global Shea Alliance (GSA) (2013) grading standards this results indicates that organic shea butter can be graded as high quality butter (grade 1). Hence, can serve the need of the cosmetic, pharmaceutical industries and for direct consumption. However, inorganic shea butter was graded as low quality shea butter (grade 3) and can serve the needs of the soap making industries or can be refined for direct consumption.

\section{Peroxide Value}

The peroxide value was significantly high in inorganic shea butter compared to the organic shea butter. This was expected as peroxide value tends to increase when the nuts are exposed to increasing temperatures (Akinoso et al., 2010). This may have been facilitated by the exposure of the nuts to the sun's radiation in cultivated areas where environmental temperatures are very high. Uncultivated areas have more ground cover and nuts tend to get shielded from the sun's radiation thereby having less exposure to high temperatures. Using the shea butter standard given by GSA (2013) the peroxide value was high for inorganic shea butter which falls under grade 3 . Hence, is recommended for soap making or further refined for direct consumption. However, the peroxide value for organic shea butter was low and graded under grade 2 which can serve the needs of the food industry for manufacturing confectionary, chocolate edible oil and a base for margarines.

$$
p H
$$

Shea butter source was found to have no significant influence on the $\mathrm{pH}$ of the shea butter though it was observed that organic shea butter was more acidic. A probable reason for the result may be that the $\mathrm{pH}$ of shea butter does not change irrespective of the conditions in which the nuts were before picking.

\section{Unsaponifiable Matter}

From the results, inorganic shea butter has about two times the amount of unsaponifiable matter contained in organic shea butter. As unsaponifiable fractions of fats and oils are generally esters, an increase in environmental temperature may have aided this phenomenon as esterification reactions are enhanced by increasing temperatures. The amount of unsaponifiable matter has been found to range from 4 to $11 \%$ by weight (Lipp and Anklam, 1998; Alander, 2004). However, the quantities for unsaponifiable matter from the treatments were very high, especially for the inorganic shea butter.

Table 1 Chemical composition of organic and inorganic shea butter

\begin{tabular}{l|ccccc}
\hline \multicolumn{1}{c|}{ Parameter $(\%)$} & $\begin{array}{c}\text { Inorganic shea butter } \\
(\text { Mean } \pm \text { SD) }\end{array}$ & $\begin{array}{c}\text { Organic shea butter } \\
(\text { Mean } \pm \text { SD) }\end{array}$ & $\begin{array}{c}\text { LSD } \\
(5 \%)\end{array}$ & P-value & $\%$ CV \\
\hline Free fatty acids & $3.76 \pm 0.057$ & $0.84 \pm 0.001$ & 0.172 & $<0.001$ \\
Peroxide value & $16.47 \pm 0.041$ & $15.06 \pm 0.023$ & 0.143 & $<0.001$ & 0.2 \\
pH & $6.84 \pm 0.177$ & $5.96 \pm 0.255$ & 0.943 & $<0.056$ & 3.4 \\
Unsaponifiable matter & $30.55 \pm 1.061$ & $12.65 \pm 1.768$ & 6.272 & $<0.007$ & 6.7 \\
Moisture content & $0.13 \pm 0.001$ & $0.11 \pm 0.007$ & 0.022 & $<0.038$ & 4.3 \\
Insoluble impurities & $3.54 \pm 0.003$ & $0.74 \pm 0.007$ & 0.023 & $<0.001$ & 0.2 \\
\hline
\end{tabular}


Table 2 Correlation coefficients of some quality characteristics of shea butter

\begin{tabular}{l|lllll}
\hline \multicolumn{1}{c|}{ Parameter } & \multicolumn{1}{c}{$\begin{array}{c}\text { Free fatty } \\
\text { acid }\end{array}$} & $\begin{array}{c}\text { Peroxide } \\
\text { value }\end{array}$ & $\mathrm{pH}$ & $\begin{array}{c}\text { Unsaponifiable } \\
\text { matter }\end{array}$ & $\begin{array}{c}\text { Moisture } \\
\text { content }\end{array}$ \\
\hline Peroxide value & $-0.9996^{* * *}$ & & & & \\
$\mathrm{pH}$ & -0.9384 & 0.9444 & & & \\
Unsaponifiable matter & $-0.9951^{* *}$ & $0.9962^{* *}$ & 0.9221 & & \\
Moisture content & $-0.9673^{*}$ & $0.9661^{*}$ & 0.8343 & $0.9826^{*}$ & $0.9629 *$ \\
Insoluble impurities & $-0.9999^{* * *}$ & $0.9994^{* * *}$ & 0.9429 & $0.9936^{* *}$ & \\
\hline
\end{tabular}

*Significant at $5 \%$, **Significant at $1 \%, * * *$ Significant at $0.1 \%$

\section{Moisture Content}

The moisture content for inorganic shea butter was higher than that of organic shea butter. The moisture contents of shea butter destined for cosmetic and food industries are required to be about $0.05 \%$ and less than $0.2 \%$, respectively (Kassamba, 1997). The results obtained from grading the two treatments using the criteria for grading butter by the GSA (2013) showed moisture content for both organic and inorganic shea butter where graded the same (grade 2). Hence, can serve the needs of food industry (confectionery, chocolate, edible oil or as basis for margarines).

\section{Insoluble Impurities}

ARS SHEA-K (2011) standard indicates that shea butter should contain at most $1 \%$ of insoluble impurities. From the results, inorganic shea butter had a higher amount of insoluble impurities than the organic shea butter. The study revealed that the amount of insoluble impurities is higher than the quality required for the inorganic shea butter. It could be that more impurities are carried along with the nuts from cultivated areas which cannot be removed during processed.

\section{Correlation Analysis of Some Quality Characteristics} of Shea Butter

The free fatty acids have a negative relationship with the peroxide value (Table 2) which was similar to the observation of Agene (2015) that peroxide value had a negative influence on stearic, linolenic and linoleic contents significantly in parboiled kernels. However, Agene (2015) result with respect to the relationship between free fatty acids and moisture content contradicts the findings of this study. This study also showed that the amount of unsaponifiable matter and insoluble impurities in shea butter correlates positively (Table 2).

\section{Conclusion}

The study was carried to a compare the chemical properties of organic shea butter and inorganic shea butter obtained from Kanfiehiyili community in the Kumbungu District of Northern Region and to determine differences in chemical quality parameters. The results of FFA, moisture content, unsaponifiable matter, peroxide value and insoluble impurities indicates that the location from which the shea nuts were collected for butter extraction have a significant effect on the quality of shea butter. The organic shea butter is of high quality (grade 1) and can serve the needs of the cosmetic and pharmaceutical industries. There was also a positive relationship between unsaponifiable matter and moisture content. Based on the finding, it is recommended that, for good quality butter, nuts should be sourced from organically certified fields.

\section{Acknowledgement}

We cannot forget of Mr. Jonathan of the Pharmacognosy laboratory of the Kwame Nkrumah University of Science and Technology for the technical support during the clinical analysis of shea butter samples.

\section{Conflict of Interest}

There is no competing interest among the authors of this research article.

\section{References}

Abedin A, Abubakari HA, Quainoo AK, Chimsah FA, Nyarko G, Mahunu GK, Abagale FK, Addai G. 2015. Preliminary studies on the effects of shea kernel size on shea butter quality. African Journal of Food Science.

Agene VN. 2015. Effect of different processing methods and periods of storage in different containers on some quality characteristics of kernel and extracted butter of shea nut. MPhil thesis, Kwame Nkrumah University of Science and Technology.

Akinoso R, Aboaba SA, Olayaanju TMA. 2010. Effect of moisture content and heat treatment on peroxide and oxidative stability of un-refined Sesame oil. African journal of Food, Agriculture, Nutrition and Development Rural outreach program, 10: 4268-4285.

Alander J. 2004. Shea butter- a multi-functional ingredient for food and cosmetics. Lipid Technol., 16: 202-205.

ARS SHEA-K 2011. African standard for Shea Kernel. The African Organization for standardization.

Boffa JM. 1999. Agroforestry parklands in Sub-Saharan Africa. Forest Conservation Guide 34. Roma: FAO.

Caroline C, Mayumi M, Mirjam VL, Mirjam T. 2009. Shea nut and butter in Ghana opportunities and constraints for local processing Wageningen University, Wageningen, Holand.

De Muelenaere G. 1997. Proposal for a directive relating to cocoa and chocolate products consequences for Exporting and Importing Countries European Union pp.34.

Ethiopian Standard ISO 18609. 2012. Animal and vegetable fats and oils - Determination of unsaponifiable matter - Method using hexane extraction (English).

Evans WC. 2002. Trease and Evans pharmacognosy, $15^{\text {th }}$ Edition. Harcourt Publishers Ltd. pp 95-98.

FAO 1988. Traditional food plants. Food and Nutrition Paper, 42: $1-593$.

GSA (Global Shea Alliance) 2013. Industry quality standards for shea kernel proposal to general assembly. GSA 001. www.globalshea. Com.

ISO 3960. 2007. Animal and Vegetable fats and oils Determination of peroxide value.

Kassamba B. 1997. Summary of known extraction and packaging techniques of shea butter in Burkina Faso. Projetfili 'erekarit'e du CECI IRSAT. IRSAT, Ouagadougou.

Lipp M, Anklam E. 1998. Review of cocoa butter and alternative fats for use in chocolate-part a compositional data. Food. Chem., 62: 73-97. 
Moore S. 2008. The role of Vitellaria paradoxa in poverty reduction and food security in the Upper East region of Ghana. Earth \& Environment, 3: 209-245.

Russo L, Etherington T. (2001). Non-wood news. An Information Bulletin on Non-Wood Forest Products, 8: 38-39.
United States Agency for International Development (USAID) 2005. Lovett P, Miller E, Mensah P, Adams V, Kannenberg C (accessed on 10/17/18). Shea Butter Exporter Guide.

Yidana JA. 2004. Progress in developing technologies to domesticate the cultivation of shea tree (Vitellaria paradoxa L) in Ghana. Agricultural and Food Science Journal of Ghana, 3: 249. 